\title{
Lifestyle and Life Satisfaction: The Role of Delayed Gratification
}

\author{
Adelina Gschwandtner ${ }^{2}$. Sarah Jewell ${ }^{1}$ - Uma S. Kambhampati ${ }^{1}$ (D)
}

Accepted: 2 August 2021 / Published online: 20 August 2021

(c) Crown 2021

\begin{abstract}
This paper considers the impact of two measures of lifestyle-the consumption of fruit and vegetables and doing exercise - on individual well-being. Since lifestyle is likely to be endogenous, we correct for this by using two dimensions of delayed gratification as instruments. The ability to delay gratification enables individuals to give greater weight to the investment component of lifestyle decisions rather than merely the affective component. Our analysis is based on the UK Understanding Society Data, which covers 40,000 UK households over time. We find that the two delayed gratification instruments are positive and significant in influencing lifestyle. In Stage 2, we find that fruit and vegetable consumption and sports activity increase life satisfaction, though the impacts vary for men and women. These results are robust across income quartiles, region, gender, education and age groups.
\end{abstract}

Keywords Wellbeing $\cdot$ Life satisfaction $\cdot$ Happiness $\cdot$ Nutrition $\cdot$ Exercise $\cdot$ Lifestyle Locus of control · Delayed gratification index

JEL Classifications I12 $\cdot$ I14 $\cdot$ I31 $\cdot$ C18 $\cdot$ D91

\section{Introduction}

In this paper, we consider the impact that current trends in lifestyle might have on the life satisfaction of individuals. In particular, there has been an increasing push towards veganism and vegetarianism and there has been a shift towards the use of cycles, walking etc., largely because of environmental concerns. However, little attention has been paid to the impact of these changes on individual wellbeing. In particular, should these changes be seen as giving up current pleasures and therefore reducing well-being or as giving us a greater sense of purpose and therefore making us feel more satisfied with our life?

The main lifestyle indicators that we are concerned with are the consumption of fruit and vegetables $(\mathrm{F} \& \mathrm{~V})$ and the amount of sports activity that an individual undertakes.

Uma S. Kambhampati

u.s.kambhampati@reading.ac.uk

1 University of Reading, Reading, United Kingdom

2 University of Kent, Kent, United Kingdom 
Received wisdom as well as a large literature indicates that lifestyle has a large and very significant impact on the physical health of individuals. There is also an increasing acceptance that it could influence the emotional well-being of individuals, though this is less well studied. In this paper, we consider the impact of lifestyle on life satisfaction, a longer term, more deliberative measure of well-being.

We analyse this issue using data from the Understanding Society Database for the UK. One of the problems with such an analysis is the potential for reverse causality, which is rife in all studies of life satisfaction. In particular, it is possible that those who have better lifestyles may have greater life satisfaction but it is also possible that those who are more satisfied with their lives will adopt better life styles. If such endogeneity exists, we would expect it to bias our estimates. To correct for this, we instrument lifestyle with a measure of delayed gratification, which asks individuals how successful they are in sticking with diets and in maintaining a longer-term perspective to the benefits of consumption. We expect that these instruments will influence the consumption of $\mathrm{F} \& \mathrm{~V}$ and exercise directly but will only influence life satisfaction through the impact they have on F\&V/Exercise.

Our paper therefore makes two significant contributions to the literature. First, it provides a good instrument for lifestyle, allowing us to produce causal estimates. In particular, it brings into the discussion the notion of the ability to delay gratification as well as having a locus of control and the impact of these variables on life satisfaction. Second, it provides an analysis of the impact that current lifestyle changes of individuals might have on well-being.

In what follows, we will begin with a review of the literature in this area before we go on to describe the Understanding Society data that we use, the empirical methods and problems and the results. We conclude by discussing limitations of our research and giving recommendations for future research directions and relevant policy implications.

\section{Literature Review}

There has long been concern regarding self-reported happiness: are people able to pronounce on their own contentment; will they be truthful; is life satisfaction so subjective that it cannot be compared across individuals; do responses depend on where, within the questionnaire, the question is anchored? Despite these concerns, life satisfaction measures have been accepted and have been seen to correlate well with brain function measures as well as with events in one's life (marriage or divorce or the level of sunshine for example). In addition, there is an acceptance that over large samples, any one of the above problems is likely to be sufficiently random that it will not affect the estimates systematically. The literature on life satisfaction has analysed a range of factors including personality (conscientiousness, extraversion etc.); environmental factors (types of house they live in, rural/ urban etc.); socio-demographic factors (age, marital status, gender etc.) and economic factors (income, employment, assets etc.).

Epicurus, an early writer drawing the link between consumption and happiness, saw consumption as a means for happiness. Often seen as a hedonist, he argued that pleasure is the final end and should therefore determine the choices we make. However, while pleasure is to be sought after, pain is to be avoided and therefore pleasures that lead to pain in the long run should be shunned. The conclusion Epicurus came to was that a simple vegetarian diet and the company of friends in a modest garden were sufficient for happiness. What 
enables Epicurus to move from happiness as desire fulfilment to practical asceticism is that he sees pleasure as the satisfaction of desire and the strongest desire in humans is for the removal of pain (Kenny \& Kenny, 2011).

Aristotle maintained that people require both enjoyable experiences (pleasure) and a sense of purpose to be happy (Ross, 1956). Mill (1859), in turn, argued that humans can distinguish between different pleasures in terms of quantity and quality and therefore happiness can be redefined as: 'an existence exempt as far as possible from pain, and as rich as possible in enjoyments, both in point of quantity and quality'.

The distinction between consumption-fuelled pleasure and longer term analytical wellbeing has long been analysed in both the economics and the neuroscientific literature. McClure et al (2006), in a study analysing the response to drink rewards, conclude that the affective versus analytical distinction drawn by Loewenstein (1996) as well as the automatic versus controlled processes discussed by Posner and Snyder (1975) and Cohen et al. (1990) are confirmed by neuroscientific evidence. They find that subjects discount drink rewards (water and juice) available 5 minutes from the present by more than $50 \%$ relative to immediate rewards. However, when both rewards are delayed (20 minutes versus 25 minutes), there is little discounting. This is evidenced by the fact that activity in the limbic system decays rapidly as rewards are delayed, whereas activity in the frontal or parietal systems seems less sensitive to such delays. This result is supported by Bjork et al. (2009) who find that discounting of delayed rewards correlates with proportional lateral frontocortical gray matter. Figner et al. (2010) find that when the function of the left (but not right) lateral prefrontal cortex was disrupted, immediate rewards were more likely to be chosen than larger delayed rewards. Hence, the ability to delay gratification is strongly correlated with brain function.

Loewenstein et al. (2015) and Ruhm (2012) develop a 'dual decision model' in which decisions are influenced by two parts of the brain, the "affective" system and the "deliberative" system. The affective system, which coordinates sensory inputs to generate emotional states like anger or happiness, leads to instinctive consumption. The deliberative system incorporates higher cognitive processes, such as abstract thinking and planning, which account for long-term consequences of actions. In the context of diet, the affective system responds positively to a diet high in fat, sugar, carbohydrates and meat and results in instant gratification. The deliberative system recognises the importance of $F \& V$ and exercise and leads to delayed gratification (DG). In these models, as in Benhabib and Bisin (2005), selfcontrol plays an important role.

The conflict between the rational and emotional selves has also been discussed by Thaler and Shefrin (1981) who use a dual performance structure, in which individuals behave as if they have two sets of coexisting and mutually inconsistent preferences-one concerned with the long run and the other with the short run. The long run Self is a planner with a lifetime horizon and the short run Self is a doer who is myopic and concerned only with current consumption. Self-control would involve trade-offs between these two selves (page 611, Shefrin \& Thaler, 1988) though the conflict between the two selves can be resolved by altering incentives (through monitoring effort or outcomes, for instance, calorie counting) or by setting up rules which serve as pre-commitment devices (going to weight clinics or avoiding the purchase of cheesecake) (Thaler \& Shefrin, 1981). Fudenberg and Levine (2006) extend the dual selves model and argue that such models can help explain experimental evidence which indicates that increased cognitive load makes temptations harder to resist.

We now turn to the literature on lifestyle and wellbeing. Grossman (1972) puts forward a model in which individuals are both producers and consumers of health. Health is a stock 
that requires continuous "investments" over time. Investment in health is costly as consumers must trade off time and resources devoted to health, such as exercising at a local gym or eating healthy food, against other goals. These factors are seen to determine the optimal level of health that an individual will demand. Analysing the relationship between organic food consumption and health in Germany in 2007, Welsch (2012) finds a strong and statistically significant relationship between these variables. However, when he instrumented organic food consumption, the relationship vanished. Blanchflower et al. (2013) found that both happiness and mental health increase with F\&V consumption, peaking at 7 portions in the UK. However, they do not correct for reverse causality in their estimates. Grant et al. (2009) analyse life satisfaction amongst students in the UK and find that it is positively associated with physical exercise and fruit intake. Mujcic and Oswald (2016) examined longitudinal food diaries of Australian adults and found that increased F\&V consumption predicted happiness. In particular, life satisfaction increased by 0.24 life-satisfaction points when $\mathrm{F} \& \mathrm{~V}$ consumption increased by 8 portions a day. They conclude that 'people's motivation to eat healthy food is weakened by the fact that physical health benefits accrue decades later, but well-being improvements from increased consumption of fruit and vegetables are closer to immediate'. These studies however have highlighted associations between food and life satisfaction and have not considered causality directly. ${ }^{1}$

Analysing instead, the determinants of healthy eating, Graham et al. (2004) found that in Russia from 1995-2000, happier people did take better care of their health and could therefore have a healthier lifestyle. Cobb-Clark et al. (2014) found that individuals with an internal locus of control were more likely to eat well and exercise regularly in Australia. Men with an internal locus of control expect to have higher health returns to their investments in diet and exercise. Women with an internal locus of control maintain healthy habits because they derive greater satisfaction from those activities than women with external control tendencies.

Overall, we note that lifestyle may have different short vs long run, physical vs wellbeing and affective vs deliberative-effects. Thus, a run may be painful in the short term but once it is over, it may give the individual a high and in the long run may improve wellbeing. It may also have different physical and wellbeing effects: eating a burger and fries or a chocolate bar may give us immediate pleasure but may make us feel lethargic and unhappy in the slightly longer term. Finally, there may be different affective and deliberative effects: eating fried food may give us immediate affective pleasure but not deliberative well-being. In this paper, we analyse the impact of lifestyle on long run, deliberative well-being. To do this, we model lifestyle as being dependent on the ability to take a longer term perspective on consumption and exercise.

\section{Data}

In this paper, we use the UK Understanding Society Data, which began in 2009 as a successor to the UK BHPS longitudinal survey. The survey has a sample of 40,000 UK households over time and we use wave 5 (and the general population sample) as this is the wave where the delayed gratification questions are asked alongside the fruit/veg and sports activity questions. The dataset currently has 9 waves though we only use Wave 5 for the analysis

\footnotetext{
${ }^{1}$ Except for maybe Granger type (Mujcic \& Oswald, 2016).
} 
in this paper, as this is the only wave in which both the delayed gratification questions and the questions in relation to lifestyle have been asked. We use data for 14,159 individuals (5926 men and 8233 women).

\section{Estimation Methodology}

The basic model we are interested in is:

$$
\text { Life Satisfaction }_{i}=a_{1}+b X_{i}^{\prime}+c_{1} \text { Lifestyle }_{i}+e_{i}
$$

where $i$ denotes the individual, $X^{\prime}$ includes observable controls such as age, gender, employment status, marital status etc. Lifestyle is $\mathrm{F} \& \mathrm{~V}$ consumption or exercise and $e_{i}$ is an error term. Our wellbeing measure is life satisfaction and we use two measures of lifestyle - fruit and vegetable consumption and sports activity.

As already mentioned earlier, we would expect lifestyle to be endogenous in the above model. Such endogeneity could arise for many reasons including measurement error, omitted variable bias, discount rate bias and, of course, reverse causality. The last, in particular, is very common in studies of life satisfaction because we might expect that while lifestyle will affect life satisfaction, individuals who are satisfied with their life are also likely to adopt healthier lifestyles (see also Graham, Eggers et al., 2004). We attempt to correct for this endogeneity by estimating an Instrumental Variables (IV) model in which the ability to delay gratification (DGI) is the instrument which identifies the exogenous variation in the consumption of fruit and vegetables as well as sports activity. The identified $\mathrm{F} \& \mathrm{~V}$ consumption and sports activity variables then enter into stage 2 of our estimation. Thus, we argue that individuals who are able to delay gratification are more likely to have healthy lifestyles (to consume $\mathrm{F} \& \mathrm{~V}$ and to do exercise) than individuals who want instant gratification. $^{2}$

For DGI to be an appropriate instrument, it should not affect life satisfaction directly or through other pathways. In particular, we are concerned with the possibility that the ability to delay gratification might directly influence life satisfaction by giving us a greater sense of control over our lives. If we want to capture the precise impact of F\&V/Exercise on life satisfaction, we will need to control for this direct effect. To do this, we include a variable called Locus of Control in the life satisfaction model, which will help us to capture the extent to which a sense of control will influence life satisfaction. Individuals are asked in wave 2 whether they agree with the statement that what happens in life is beyond their control, with options of 1 (Strongly agree) to 6 (Strongly disagree): a higher value represents individuals who have a higher internal locus of control. Since this is also likely to influence lifestyle, we include it in both stages of the estimation. Once this is accounted for, we might expect that all impact of DGI will be through F\&V/Exercise. Thus, we estimate the following:

$$
\text { Life Style }_{i}=\alpha+\beta X_{i}^{\prime}+\delta L O C_{i}+\gamma D G I_{i}++u_{i} \text { Stage } 1
$$

\footnotetext{
${ }^{2}$ It is worth qualifying that this does not exclude the possibility that healthy eating and moderate sports can have significant and positive short term effects too. If, for example, F\&V and exercise are a source of pleasure in the short run, this would enable the individual to consume F\&V and exercise in the current moment, thereby increasing their ability to stick with the healthy lifestyle in the long run.
} 


$$
\text { Life Satisfaction }_{i}=\kappa+\rho X_{i}^{\prime}+\pi \text { Lifestyle }_{i}+\phi L O C_{i}+U_{i} \text { Stage } 2
$$

$X_{i}^{\prime}$ (the subscript should be lower case) are the usual controls that one would expect in a model of life satisfaction. These include a range of demographic controls including age, ${ }^{3}$ marital status (whether married, cohabiting or not living with a spouse/partner), ethnicity, age of youngest child, highest qualification, employment status and the log of monthly household income (adjusted for household size, using the OECD equivalence scale) and long term health status.

Our instrument in stage 1 are two components of the DGI i.e. the ability to delay gratification or the tendency to forego strong immediate satisfaction for the sake of long-term rewards. The National Institute of Health (2009) guidelines identify gratification delay as having a significant impact on public health. The Understanding Society survey uses a 5-factor Delaying Gratification Inventory (DGI) reflecting the ability of individuals to delay gratification in the following five domains: Food, Physical, Social, Money and Achievement (Hoerger et al., 2011). The questions capture the extent to which individuals are willing to give up short-term satisfaction for longer-term rewards based on their answer to 10 questions related to the five domains mentioned above. These answers are summarised in one variable called 'Delayed Gratification'. This is only asked once in Wave 5 of the Survey and this is therefore the wave we use for the analysis in this chapter. The two components we use as instruments both relate to delaying gratification with regard to food:

Delay 1: I would have a hard time sticking with a special, healthy diet (reverse coded)

Delay 8: I have always tried to eat healthy because it pays off in the long run

As discussed above, we also include a variable to capture the extent of control individuals feel they have over their lives. This is especially because delaying gratification may influence both $\mathrm{F} \& \mathrm{~V}$ consumption and life satisfaction by enabling individuals to feel they have control over their lives. Including this variable directly in both stages allows us to control for its effect. Cobb-Clark et al. (2014) have shown that individuals with an 'internal' as opposed to an 'external' locus of control are more likely to have healthy habits such as eating well and exercising regularly, drinking moderately and avoiding tobacco.

\subsection{Variables}

Life satisfaction is measured from responses to the question: "Please choose the number which you feel best describes how dissatisfied or satisfied you are with the following aspects of your current situation: Life overall”. The responses are on a seven-point scale (1 is not satisfied at all and 7 is completely satisfied). We treat life satisfaction as a continuous variable rather than an ordered variable as studies have shown there is little difference to results in treating life satisfaction as a continuous or ordered variable (Ferrer-i-Carbonell \& Frijters, 2004).

We also consider two sets of lifestyle behaviours - food related and activity related. The portions of fruit and vegetables consumed per day by an individual on a scale of less than $1(\operatorname{coded} 1), 1-2(\operatorname{coded} 2) \ldots .7+(\operatorname{coded} 8)$ and sports activity on a scale of 0 (no sport at all) to 10 (very active).

In the next section, we will consider the results of our estimations.

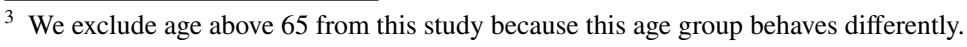


Table 1 Impact of lifestyle on life satisfaction

\begin{tabular}{|c|c|c|c|c|}
\hline & Fruit/veg & & Sports acti & \\
\hline & OLS & IV & OLS & IV \\
\hline Female & 0.040 & $-0.058^{* *}$ & $0.109 * * *$ & $0.188 * * *$ \\
\hline & {$[0.025]$} & {$[0.029]$} & {$[0.025]$} & {$[0.027]$} \\
\hline Portions of fruit and veg & $0.064 * * *$ & $0.253 * * *$ & & \\
\hline & {$[0.007]$} & {$[0.025]$} & & \\
\hline Sports activity & & & $0.054 * * *$ & $0.176 * * *$ \\
\hline & & & {$[0.004]$} & {$[0.017]$} \\
\hline Control over life & $0.102 * * *$ & $0.084 * * *$ & $0.101 * * *$ & $0.086^{* * * *}$ \\
\hline & [0.009] & {$[0.010]$} & [0.009] & {$[0.010]$} \\
\hline First stage results & & & & \\
\hline Female & & $0.423 * * *$ & & $-0.787 * * *$ \\
\hline & & {$[0.030]$} & & {$[0.046]$} \\
\hline Control over life & & $0.074 * * *$ & & $0.096 * * *$ \\
\hline & & {$[0.011]$} & & [0.017] \\
\hline Delay 1 & & $0.082 * * *$ & & $0.129 * * *$ \\
\hline & & {$[0.005]$} & & {$[0.008]$} \\
\hline Delay 8 & & $0.159 * * *$ & & $0.216^{* * *}$ \\
\hline & & {$[0.006]$} & & {$[0.010]$} \\
\hline Controls & Yes & Yes & Yes & Yes \\
\hline Obs & 14,159 & 14,159 & 14,159 & 14,159 \\
\hline$R$-squared & 0.114 & 0.063 & 0.117 & 0.070 \\
\hline IV F test & & 608.3 & & 526.5 \\
\hline Overid Hansen J Test (Chi-sq) & & 0.532 & & 1.551 \\
\hline Overid P-value & & 0.473 & & 0.218 \\
\hline Endog test (Chi-sq): DWH robust & & 65.84 & & 55.88 \\
\hline Endog P-value & & 0 & & 0 \\
\hline
\end{tabular}

Robust standard errors in brackets

Includes controls for white, age group, marital status, age of the youngest child, highest qualification, economic activity, log of equivalised (by the OECD equivalence scale) household income, urban area, long standing illness

Delay 1 is reverse coded and refers to the question "I would have a hard time sticking with a special, healthy diet"

Delay 8 refers to the question "I have always tried to eat healthy because it pays off in the long run" $* * * \mathrm{p}<0.01, * * \mathrm{p}<0.05, * \mathrm{p}<0.1$

\section{Results}

Table 1 below provides the results of both the Stage 1 and Stage 2 estimates of our IV model as well as the OLS estimates for comparison. In what follows, we present the coefficients of only those variables that are central to our analysis. Table 8 in the Appendix provides the summary statistics for all the variables used in our analysis and Table 9 provides the full set of results, including for the controls. 
Starting with the Stage 1 results, we see that both the DG indicators (Delay 1 and Delay 8) that we use as instruments are positive and highly significant both for F\&V consumption and for sports activity. Both of these delay variables have a larger impact on sports activity than on F\&V consumption. The coefficient of the female variable in our Stage 1 results indicates that women eat more $\mathrm{F} \& \mathrm{~V}$ than men and do less sports activity. Additionally, both instruments-Delay 1 and Delay 8 - are positive and highly significant in determining F\&V consumption. More precisely, Delay 8 (eating healthy because it pays off in the long run) has a larger impact than Delay 1 (the ability to stick to a diet) confirming that it is the ability to think of the long run that is crucial.

Turning to the Stage 2 estimates, we see first from the endogeneity test that with $99 \%$ confidence we can reject the hypothesis that our life-style variables are exogenous, thus justifying the use of instrumental variables in the models. We present here the results of a version of the Durbin-Wu-Hausman test valid for robust standard errors (Hayashi, 2000, pp. 233-34). We see that the Chi-squared value is very large and the P-value is very small indicating that our lifestyle variables are endogenous and need instrumentation. Our instruments also pass the over-identification Hansen $\mathbf{J}$ Test. The test statistic is not significant suggesting that we can reject the null of over-identification. The F-test value is very high, substantially above any typical threshold, confirming that both instruments are 'good' instruments.

As a robustness check we run our estimates using Delay 1 alone and Delay 8 by itself as instruments, and our results are similar, which provides further support that our instruments are valid. The results for these are provided in Table 10 in the Appendix.

We see a few more patterns. First, all the coefficients (both OLS and IV) are highly significant and positive indicating that both $\mathrm{F} \& \mathrm{~V}$ and sports have a positive relationship with life satisfaction. Second, we see that the OLS coefficients are all downward biased and the IV estimates are higher than the OLS coefficients. Our results therefore lead us to conclude that both $\mathrm{F} \& \mathrm{~V}$ consumption and exercise have a significant positive impact on life satisfaction.

\subsection{Heterogeneity of Impacts}

Our results so far clearly indicate that delaying gratification is a significant instrument for $\mathrm{F} \& \mathrm{~V}$ consumption as well as sports activity (Stage 1). They also indicate that F\&V consumption and sports activity are significant in influencing life satisfaction for both men and women (Stage 2). In this section, we will consider whether these results remain consistent across various characteristics. In particular, it is possible that the impact of lifestyle on life satisfaction might be different across gender, education, income quartiles, age groups, in rural vs urban areas and so on. We will explore some of these relationships in order to establish the robustness of our results.

The summary statistics in Table 2 below indicate that F\&V consumption and sports activity increase monotonically with income quartiles as do the ability to delay gratification and the sense of control. There is no causality implicit here, only the association can be noted. The table also indicates that consumption increases by age group but, not surprisingly, sports activity decreases. The patterns of DG and sense of control are not clear. It is worth noting that life satisfaction is increasing monotonically across income groups; is higher in rural areas and lowest in the 25-54 age group.

The summary statistics for our heterogeneity variables are presented in Table 2 . All values are statistically significantly different by characteristic except for life satisfaction scores 
Table 2 Summary Statistics by income, education, age and region

\begin{tabular}{|c|c|c|c|c|c|c|c|}
\hline & \multirow[t]{2}{*}{ Obs } & \multicolumn{6}{|l|}{ Mean } \\
\hline & & Life sat & Fr/Veg & Sports & Control & Delay 1 & Delay 8 \\
\hline \multicolumn{8}{|l|}{ Gender } \\
\hline Men & 5926 & 4.985 & 3.577 & 3.959 & 3.162 & 5.117 & 5.875 \\
\hline Women & 8233 & 5.021 & 4.070 & 3.261 & 3.051 & 5.257 & 6.388 \\
\hline \multicolumn{8}{|c|}{ Income quartile } \\
\hline 1 & 3200 & 4.568 & 3.327 & 2.815 & 2.829 & 5.001 & 5.880 \\
\hline 2 & 3504 & 4.916 & 3.744 & 3.213 & 2.930 & 5.036 & 6.123 \\
\hline 3 & 3660 & 5.141 & 3.959 & 3.680 & 3.141 & 5.225 & 6.156 \\
\hline 4 & 3795 & 5.329 & 4.335 & 4.368 & 3.435 & 5.490 & 6.484 \\
\hline \multicolumn{8}{|c|}{ Above/below median income } \\
\hline Below & 6704 & 4.750 & 3.545 & 3.023 & 2.882 & 5.019 & 6.007 \\
\hline Above & 7455 & 5.237 & 4.150 & 4.030 & 3.290 & 5.360 & 6.323 \\
\hline \multicolumn{8}{|c|}{ In top income quartile } \\
\hline No & 10,364 & 4.888 & 3.691 & 3.255 & 2.974 & 5.092 & 6.059 \\
\hline Yes & 3795 & 5.329 & 4.335 & 4.368 & 3.435 & 5.490 & 6.484 \\
\hline \multicolumn{8}{|l|}{ Degree } \\
\hline No & 9916 & 4.909 & 3.603 & 3.248 & 2.946 & 5.075 & 6.003 \\
\hline Yes & 4243 & 5.233 & 4.472 & 4.267 & 3.451 & 5.487 & 6.570 \\
\hline Rural area & 3506 & 5.114 & 4.082 & 3.657 & 3.119 & 5.238 & 6.288 \\
\hline Urban area & 10,653 & 4.971 & 3.792 & 3.519 & 3.090 & 5.185 & 6.136 \\
\hline \multicolumn{8}{|l|}{ Age group } \\
\hline Under 25 & 1224 & 5.190 & 3.129 & 4.685 & 3.289 & 5.114 & 5.556 \\
\hline $25-54$ & 9441 & 4.985 & 3.833 & 3.690 & 3.146 & 5.196 & 6.106 \\
\hline $55-64$ & 3494 & 5.000 & 4.203 & 2.787 & 2.898 & 5.235 & 6.571 \\
\hline Total & 14,159 & 5.006 & 3.864 & 3.553 & 3.097 & 5.199 & 6.173 \\
\hline
\end{tabular}

Delay 1 is reverse coded and refers to the question "I would have a hard time sticking with a special, healthy diet"

All values are statistically significantly different by characteristic except:

Life satisfaction is not statistically significantly different by gender

Delay 8 not statistically significantly different between income quartile 2 and 3

Control is not statistically significantly different between rural and urban

for men and women. On a scale of 1-7, the average for men is 4.99 and for women is 5.02 . Turning to the consumption of $\mathrm{F} \& \mathrm{~V}$, we find that men consumed 3.58 portions of $\mathrm{F} \& \mathrm{~V}$, while women consumed 4.07 portions. Thus, women consume significantly more F\&V than men but men do significantly more sports than women with a score of 3.96 against 3.26 for women. Finally, the table indicates that women have significantly better ability to delay gratification when considering the longer term payoff of healthy eating (delay 8) than men do. While this is also true for the ability to stick to a diet (Delay 1), the difference here is much smaller. Overall, therefore, our summary statistics indicate that women have better consumption habits and give greater weight to the long run when making these decisions.

Turning to differences across income quartiles, we find that both F\&V consumption and sports activity differ across income quartiles, as does life satisfaction. These differences are all significant. The ability to delay gratification (Delay 1 ) is significantly different between 
Table 3 Heterogeneity by gender

\begin{tabular}{|c|c|c|c|c|}
\hline \multirow[t]{2}{*}{ Dep Var: Life-satisfaction } & \multirow{2}{*}{$\begin{array}{l}\mathrm{F} \& \mathrm{~V} \\
\text { OLS }\end{array}$} & \multicolumn{3}{|c|}{ Sports activity } \\
\hline & & IV & OLS & IV \\
\hline \multirow[t]{2}{*}{ Female } & 0.039 & 0.056 & $0.158 * * *$ & 0.182 \\
\hline & {$[0.056]$} & {$[0.161]$} & {$[0.041]$} & {$[0.116]$} \\
\hline \multirow[t]{2}{*}{ Portions of F\&V } & $0.064 * * *$ & $0.269 * * *$ & & \\
\hline & {$[0.010]$} & [0.034] & & \\
\hline \multirow[t]{2}{*}{ Portions of $\mathrm{F} \& \mathrm{~V} *$ female } & 0.001 & -0.030 & & \\
\hline & {$[0.013]$} & {$[0.042]$} & & \\
\hline \multirow[t]{2}{*}{ Sports activity } & & & $0.061 * * *$ & $0.174 * * *$ \\
\hline & & & {$[0.006]$} & {$[0.023]$} \\
\hline \multirow[t]{2}{*}{ Sports activity* female } & & & -0.013 & 0.002 \\
\hline & & & {$[0.008]$} & {$[0.031]$} \\
\hline \multirow[t]{2}{*}{ Control over life } & $0.102 * * *$ & $0.084 * * *$ & $0.101 * * *$ & $0.086^{* * *}$ \\
\hline & {$[0.009]$} & {$[0.010]$} & {$[0.009]$} & {$[0.010]$} \\
\hline Obs & 14,159 & 14,159 & 14,159 & 14,159 \\
\hline$R$-squared & 0.114 & 0.064 & 0.117 & 0.07 \\
\hline IV F test & & 302.4 & & 168.3 \\
\hline Overid Hansen J Test (Chi-sq) & & 1.551 & & 2.974 \\
\hline Overid P-value & & 0.453 & & 0.226 \\
\hline \multicolumn{5}{|l|}{ Endog test (Chi-sq) } \\
\hline \multicolumn{2}{|l|}{ DWH robust } & 65.23 & & 55.63 \\
\hline \multicolumn{2}{|l|}{ Endog $P$-value } & 0 & & 0 \\
\hline
\end{tabular}

Zeros are correctly rounded up from 0.000

Robust standard errors in brackets

Includes controls for white, age group, marital status, age of the youngest child, highest qualification, economic activity, log of equivalised (by the OECD equivalence scale) household income, urban area, long standing illness

$* * * \mathrm{p}<0.01, * * \mathrm{p}<0.05, * \mathrm{p}<0.1$

quartile 1 and quartile 4 (with people in the highest income quartile being able to stick to a diet significantly better than in the lowest) but the difference is not significant between quartile 1 and 2. Delay 8 is not significantly different between quartiles 2 and 3 but is significantly different across all other quartiles. People in the highest income quartile appear to be able to delay gratification better than people in the lowest. These differences are confirmed in the above/below median sub-samples.

Table 2 also indicates that $F \& V$ consumption and sport activity do vary by education. In particular, those with a degree consume more $\mathrm{F} \& \mathrm{~V}$ and also do more exercise than those without a degree. The summary statistics also indicate that they are significantly more likely to say they have control over their lives and able to delay gratification than those without degrees. While rural areas consume more $\mathrm{F} \& \mathrm{~V}$ and do more sports, there is no significant difference in their sense of control or their ability to delay gratification from urban areas. Finally, the differences in life satisfaction, lifestyle and control as well as delayed gratification are significant across all age groups that we consider (15-24, 25-54 and 55-64 year olds) (Table 3). 
Table 4 Heterogeneity across income quartiles (top quartile versus other quartiles)

\begin{tabular}{|c|c|c|c|c|}
\hline \multirow[t]{2}{*}{ Dependent Var: Life satisfaction } & \multicolumn{2}{|l|}{$\mathrm{F} \& \mathrm{~V}$} & \multicolumn{2}{|c|}{ Sports activity } \\
\hline & OLS & IV & OLS & IV \\
\hline \multirow[t]{2}{*}{ Portions of F\&V } & $0.074 * * *$ & $0.271 * * *$ & & \\
\hline & {$[0.008]$} & {$[0.029]$} & & \\
\hline \multirow[t]{2}{*}{ Sports activity } & & & $0.063 * * *$ & $0.202 * * *$ \\
\hline & & & {$[0.005]$} & {$[0.022]$} \\
\hline \multirow[t]{2}{*}{ In top quartile } & $0.341 * * *$ & $0.452^{* *}$ & $0.299 * * *$ & $0.433 * * *$ \\
\hline & {$[0.066]$} & {$[0.187]$} & {$[0.049]$} & {$[0.142]$} \\
\hline \multirow[t]{2}{*}{$\mathrm{F} \& \mathrm{~V} *$ In top quartile } & $-0.032 * *$ & -0.070 & & \\
\hline & {$[0.014]$} & {$[0.044]$} & & \\
\hline \multirow[t]{2}{*}{ Sports activity * In top quartile } & & & $-0.028^{* * * *}$ & $-0.081^{* *}$ \\
\hline & & & {$[0.009]$} & {$[0.034]$} \\
\hline Observations & 14,159 & 14,159 & 14,159 & 14,159 \\
\hline$R$-squared & 0.111 & 0.061 & 0.115 & 0.063 \\
\hline$I V F$-test & & 287.8 & & 180.1 \\
\hline Overid Hansen J Test (Chi-sq) & & 0.015 & & 0.369 \\
\hline Overid P-value & & 0.828 & & 0.458 \\
\hline Endog Test (Chi-sq) DWH robust & & 64.92 & & 55.23 \\
\hline Endog P-Value & & 0 & & 0 \\
\hline
\end{tabular}

Zeros are correctly rounded up from 0.000

Robust standard errors in brackets

Includes controls for gender, control over life, white, age group, marital status, age of the youngest child, highest qualification, economic activity, urban area, long standing illness

$* * * \mathrm{p}<0.01, * * \mathrm{p}<0.05, * \mathrm{p}<0.1$

In what follows, we consider whether there is heterogeneity of our results across subsamples. Considering first the differences across gender, we confirm, once again, that both $\mathrm{F} \& \mathrm{~V}$ consumption and sports activity have a positive significant impact on life satisfaction. The diagnostic statistics indicate that lifestyle and life-satisfaction are endogenous and therefore instrumentation was necessary. The instruments pass the overidentification test and the F-test value is above the recommended threshold. However, there appears to be no significant difference in the impact that these variables have on life-satisfaction by gender. This is clear from the insignificance of the coefficient of the interaction term between gender and the two lifestyle variables and confirms the patterns indicated by our summary statistics.

Table 11 in the Appendix presents results separately by gender. These results confirm that even though both life-style dimensions have a positive and significant impact on lifesatisfaction, their impact by gender differs only marginally in our sample.

We estimate the model to consider heterogeneity across the income quartiles in 3 different ways - by estimating across the 4 income quartiles, estimating for the above and below median groups and estimating the top quartiles vs the others. All three give us very similar results and we will therefore present the results for the top quartile vs others in this section, as it makes the pattern very clear. Once again, the endogeneity tests shows that we 
can reject with high confidence that lifestyle and life-satisfaction are exogeneous. They also confirm that our instruments are strong (Table 4).

Our results indicate, as before, that F\&V consumption and sports activity have a positive, significant impact on life satisfaction. In addition, we see that being in the top quartile increases life satisfaction significantly. However, our results indicate that the interaction term between $\mathrm{F} \& \mathrm{~V}$ and the top income quartile is not significant, leading us to conclude that being in the top quartile neither increases nor decreases the impact of $F \& V$ on lifesatisfaction. Surprisingly, our results indicate that being in the top quartile and doing sports activity decreases life satisfaction. It is important to interpret this result carefully. Even in this group (top income quartile and doing sports), the impact of sports activity on life satisfaction is positive. However, the size of the impact is smaller than the impact of sports activity in the lower income quartiles. While this might seem surprising at first glance, it could arise from the fact that individuals in the top quartile might get a sense of achievement from their income rather than sporting prowess. Second, for this group, the need to do sports might decrease the time they have available for other things including their work and this therefore decreases their sense of satisfaction from doing sports. Despite this, it is worth reiterating that even in this group, sports activity has a positive impact on life satisfaction. Thus, our broad result is robust across income quartiles but we note that the size of the impact varies across income quartiles.

In Table 12 in the Appendix, we present the results separately for the top quartile and for all quartiles below the top one. While we cannot see from this table if the differences are significant across income categories, we can see that the size of the impact of both $\mathrm{F} \& \mathrm{~V}$ and sports is larger in the 'below top income quartile' than in the 'top income quartile' confirming the results above.

Our IV results (Table 5) indicate that, having a degree does not significantly influence life satisfaction. Once again, our diagnostics indicate the need for instrumentation and also that our instruments pass the over-identification test and the F-test. Additionally, amongst those with degrees, consuming more $\mathrm{F} \& \mathrm{~V}$ does not lead to higher life satisfaction. However, this is not true for sports activity. Again, it is worth emphasising that sports activity increases life satisfaction (with a coefficient of +0.191 ), even amongst those with degrees but it has a smaller positive effect for degree holders (+0.191-0.081) than for those without degrees. Again, this could be because those with a degree derive a higher life-satisfaction from achievements other than sports and because sports reduces their time for other activities.

This can be clearly seen from Table 13 in the Appendix where the results are presented separately for those with a degree and those without. The results show that while both lifestyle variables have a positive and significant impact on life-satisfaction for those with and those without a degree, the impact is larger in the 'No degree' category. Again, the results in Table 13 corroborate the ones in Table 5 above.

Even though both F\&V and Sports Activity have a positive and significant impact on life-satisfaction, and even though our summary statistics indicated that those living in rural areas eat more $\mathrm{F} \& \mathrm{~V}$ and do more exercise, our results in Table 6 reveal that there are no significant urban/rural differences in terms of the effect of lifestyle on life-satisfaction. The coefficients of the interaction terms between lifestyle and rural/urban are not significant. These results are reinforced by the ones in Table 14 in the Appendix, where we present the results separately by regional division. The results in Table 14 show that even though the coefficients of $\mathrm{F} \& \mathrm{~V}$ and Sports Activity are larger in the rural area, the difference is only marginal. Hence the results are robust across this regional division as well. 
Table 5 Heterogeneity by education (by degree)

\begin{tabular}{|c|c|c|c|c|}
\hline \multirow[t]{2}{*}{ Dep Variable: Life satisfaction } & \multicolumn{2}{|l|}{$\mathrm{F} \& \mathrm{~V}$} & \multicolumn{2}{|c|}{ Sports activity } \\
\hline & OLS & IV & OLS & IV \\
\hline \multirow[t]{2}{*}{ Portions of F\&V } & $0.072 * * *$ & $0.259 * * *$ & & \\
\hline & {$[0.008]$} & [0.029] & & \\
\hline \multirow[t]{2}{*}{ Sports activity } & & & $0.062 * * *$ & $0.191 * * *$ \\
\hline & & & [0.005] & [0.023] \\
\hline \multirow[t]{2}{*}{ Degree } & $0.138 * *$ & -0.017 & $-0.022^{* *}$ & -0.042 \\
\hline & {$[0.064]$} & {$[0.188]$} & {$[0.009]$} & {$[0.034]$} \\
\hline \multirow[t]{2}{*}{ F\&V*Degree } & -0.021 & -0.016 & & \\
\hline & {$[0.014]$} & {$[0.044]$} & & \\
\hline \multirow[t]{2}{*}{ Sports activity* Degree } & & & $-0.028 * * *$ & $-0.081^{* *}$ \\
\hline & & & {$[0.009]$} & {$[0.034]$} \\
\hline Observations & 14,159 & 14,159 & 14,159 & 14,159 \\
\hline$R$-squared & 0.113 & 0.062 & 0.117 & 0.067 \\
\hline IV F-test & & 248.5 & & 164.4 \\
\hline Overid Hansen J Test (Chi-sq) & & 2.072 & & 4.055 \\
\hline Overid P-value & & 0.354 & & 0.130 \\
\hline Endog Test (Chi-sq) DWH robust & & 66.66 & & 55.21 \\
\hline Endog P-Value & & 0 & & 0 \\
\hline
\end{tabular}

Zeros are correctly rounded up from 0.000

Robust standard errors in brackets

$* * * \mathrm{p}<0.01, * * \mathrm{p}<0.05, * \mathrm{p}<0.1$

Includes controls for gender, control over life, white, age group, marital status, age of the youngest child, $\log$ of equivalised (by the OECD equivalence scale) household income, economic activity, urban area, long standing illness

Finally, Table 7 provides the results across three age categories: 16-24, 25-54 and 55-64 year olds. In these estimations, the instruments do not pass the over-identification test. However, we present the results for comparison purposes. These results indicate that the effect of lifestyle reduces with age (which only shows up in the IV estimates). ${ }^{4}$ There is significant heterogeneity across age groups. To start with, it seems clear that the young (16-24 year olds) and the old (55-64) have higher life satisfaction than the middle aged. Interacting age group with $\mathrm{F} \& \mathrm{~V}$ consumption, we find that there are significant negative coefficients for both these age groups indicating that amongst the 16-24 year olds, life satisfaction is lower if they have to eat $\mathrm{F} \& \mathrm{~V}$ compared to the middle age groups (a coefficient of -0.185$)$. This is also true for the 55-64 year olds $(-0.146)$. It is important to emphasise that, despite this, the coefficient for this group is positive i.e. that F\&V consumption does increase life satisfaction $(0.746-0.146)$ even for this group [though the increase would be smaller than for the 25-54 year olds (1.208-0.185)].

\footnotetext{
${ }^{4}$ Since the instruments were not exogenous when we split by age-especially for the age 55-64 group-we reduced the controls slightly. In particular, as the younger group had few in the divorced, separate or widowed group and some of the job status groups are age dependent (education, retired) so we only included employed and unemployed versus inactive.
} 
Table 6 Heterogeneity by region (urban vs rural differences)

\begin{tabular}{|c|c|c|c|c|}
\hline \multirow[t]{2}{*}{ Dep Variable: Life satisfaction } & \multicolumn{2}{|l|}{$\mathrm{F} \& \mathrm{~V}$} & \multicolumn{2}{|c|}{ Sports activity } \\
\hline & OLS & IV & OLS & IV \\
\hline \multirow[t]{2}{*}{ Portions of F\&V } & $0.063 * * *$ & $0.251 * * *$ & & \\
\hline & {$[0.013]$} & {$[0.042]$} & & \\
\hline \multirow[t]{2}{*}{ Sports activity } & & & $0.058 * * *$ & $0.167 * * *$ \\
\hline & & & {$[0.008]$} & {$[0.032]$} \\
\hline \multirow[t]{2}{*}{ Urban } & -0.072 & -0.047 & -0.048 & -0.094 \\
\hline & {$[0.066]$} & {$[0.185]$} & {$[0.046]$} & {$[0.137]$} \\
\hline \multirow[t]{2}{*}{$\mathrm{F} \& \mathrm{~V} *$ Urban } & 0.001 & 0.003 & & \\
\hline & {$[0.014]$} & {$[0.045]$} & & \\
\hline \multirow[t]{2}{*}{ Sports activity * Urban } & & & -0.006 & 0.013 \\
\hline & & & {$[0.009]$} & {$[0.037]$} \\
\hline Observations & 14,159 & 14,159 & 14,159 & 14,159 \\
\hline$R$-squared & 0.114 & 0.063 & 0.117 & 0.070 \\
\hline IV F-test & & 288.5 & & 64.83 \\
\hline Overid Hansen J-Test (Chi-sq) & & 1.256 & & 2.192 \\
\hline Overid P-value & & 0.514 & & 0.327 \\
\hline Endogen Test (Chi-sq) DWH robust & & 65.89 & & 55.79 \\
\hline Endog P-value & & 0 & & 0 \\
\hline
\end{tabular}

Zeros are correctly rounded up from 0.000

Robust standard errors in brackets

Includes controls for gender, control over life, white, age group, marital status, age of the youngest child, highest qualification, log of equivalised (by the OECD equivalence scale) household income, economic activity, long standing illness

$* * * \mathrm{p}<0.01, * * \mathrm{p}<0.05, * \mathrm{p}<0.1$

The same pattern is clear for sports activity, where once again, the age group* sports activity coefficients are negative and significant. They lead us to conclude that within the 16-24 year olds, doing sports activity decreases life satisfaction below those who do not $(-0.096)$, even though the impact of sports activity remains positive and significant even for this group. This is also true for the 55-64 year olds and their discount is larger than for the younger age group $(-0.116)$. Even for them, however, the impact of sports remains positive. Thus, we can conclude that our broad result - that F\&V and sports activity have a positive impact on life satisfaction-remains valid across age groups. However, the size of the coefficient varies across these groups, with the largest impact being amongst the middle aged (25-54 year olds).

The results in Table 15 in the Appendix, where the impact of lifestyle is analysed separately for each age group, confirm the ones above. The decreasing pattern of F\&V by age is clearly visible in the IV results where the coefficient decreases from 0.333 for the 16-24 years old to 0.254 for the 25-54 year olds and further to 0.203 for the 55-64 year olds. The decreasing impact of Sports Activity across age group is also clear. 
Table 7 Heterogeneity across age groups

\begin{tabular}{|c|c|c|c|c|}
\hline \multirow[t]{2}{*}{ Dep Variable: Life satisfaction } & \multicolumn{2}{|l|}{$\mathrm{F} \& \mathrm{~V}$} & \multicolumn{2}{|c|}{ Sports activity } \\
\hline & OLS & IV & OLS & IV \\
\hline Portions of $\mathrm{F} \& \mathrm{~V}$ & $\begin{array}{l}0.061 * * * \\
{[0.008]}\end{array}$ & $\begin{array}{l}0.244 * * * \\
{[0.028]}\end{array}$ & & \\
\hline Sports activity & & & $\begin{array}{l}0.059 * * * \\
{[0.005]}\end{array}$ & $\begin{array}{l}0.172 * * * \\
{[0.019]}\end{array}$ \\
\hline \multicolumn{5}{|l|}{ Age group (ref: aged 25-54) } \\
\hline Aged 16-24 & $\begin{array}{l}0.569 * * * \\
{[0.094]}\end{array}$ & $\begin{array}{l}1.208 * * * \\
{[0.132]}\end{array}$ & $\begin{array}{l}0.400^{* * *} \\
{[0.086]}\end{array}$ & $\begin{array}{l}0.780 * * * \\
{[0.105]}\end{array}$ \\
\hline Aged 55-64 & $\begin{array}{l}0.113 \\
{[0.074]}\end{array}$ & $\begin{array}{l}0.746 * * * \\
{[0.117]}\end{array}$ & $\begin{array}{l}0.306^{* * * *} \\
{[0.048]}\end{array}$ & $\begin{array}{l}0.659 * * * \\
{[0.074]}\end{array}$ \\
\hline \multicolumn{5}{|l|}{ Interaction with age group (fr/veg) } \\
\hline Aged 16-24 & $\begin{array}{c}-0.009 \\
{[0.024]}\end{array}$ & $\begin{array}{l}-0.185^{* * *} \\
{[0.035]}\end{array}$ & & \\
\hline Aged 55-64 & $\begin{array}{l}0.024 \\
{[0.015]}\end{array}$ & $\begin{array}{l}-0.146 * * * \\
{[0.029]}\end{array}$ & & \\
\hline \multicolumn{5}{|l|}{ Interaction with age group (sports) } \\
\hline Aged 16-24 & & & $\begin{array}{l}0.012 \\
{[0.014]}\end{array}$ & $\begin{array}{l}-0.096^{* * * *} \\
{[0.023]}\end{array}$ \\
\hline Aged 55-64 & & & $\begin{array}{c}-0.012 \\
{[0.010]}\end{array}$ & $\begin{array}{l}-0.116^{* * * *} \\
{[0.020]}\end{array}$ \\
\hline Observations & 14,159 & 14,159 & 14,159 & 14,159 \\
\hline$R$-squared & 0.106 & 0.074 & 0.111 & 0.082 \\
\hline$I V F$-test & & 168.2 & & 138 \\
\hline Overid Hansen J Test (Chi-sq) & & 36.54 & & 26.51 \\
\hline Overid P-value & & $6.62 \mathrm{e}-07$ & & $6.34 \mathrm{e}-05$ \\
\hline Endog Test (Chi-sq) DWH robust & & 49.71 & & 39.54 \\
\hline Endog $P$-Value & & 0 & & 0 \\
\hline
\end{tabular}

Zeros are correctly rounded up from 0.000

Robust standard errors in brackets

Includes controls for gender, control over life, white, whether live with spouse/partner, age of the youngest child, highest qualification, log of equivalised (by the OECD equivalence scale) household income, employed, unemployed, urban area, long standing illness

$* * * \mathrm{p}<0.01, * * \mathrm{p}<0.05, * \mathrm{p}<0.1$

\section{Discussion and Conclusion}

This paper considered the impact of two measures of lifestyle-the consumption of fruit and vegetables and doing exercise-on individual well-being. We instrument lifestyle by two components of the delayed gratification index because the ability to delay gratification enables individuals to give greater weight to the investment component of these decisions rather than merely the affective component. Our estimation results indicate, first, that the ability to delay gratification is significant in influencing lifestyle and this latter, in turn, has a significant impact on well-being. Testing for heterogeneity across 
gender, income groups, education, age groups and rural/urban dwellers, we find that while the size of the positive impact may vary with each category, it remains positive and significant.

While a positive correlation between lifestyle and wellbeing has been previously identified, the present results enable us to make a causal statement about the relationship between lifestyle and life-satisfaction. This is because we include a novel instrument that allows us to separate the impact of lifestyle on life satisfaction from the reverse effect of life satisfaction on lifestyle variables. The instruments we use are 2 components of the ability of individuals to delay gratification and focus on the long-term benefits of lifestyle decisions. These instruments are particularly appropriate because the consumption of F\&V and sports activity are often undertaken as investments in a healthier future rather than because they bring immediate pleasure. This implies that individuals who have the ability to delay gratification are better able to make these investments. Our First Stage results clearly indicate that the ability to delay gratification is a good instrument for these two lifestyle variables. By including a locus of control variables in stage 2, we also control for any direct effect that delayed gratification may have on life satisfaction. Our stage 2 IV estimates show clearly that $F \& V$ and sports activity (both investments in a physically healthy future) are very effective in improving subjective wellbeing.

Our results confirm those of Blanchflower et al. (2013) as well as Mujcic and Oswald (2016) who found that mental health and happiness increased with fruit and vegetable consumption. More recently, Ocean et al. (2019) conclude 'that persuading people to consume more fruits and vegetables may not only benefit their physical health in the long-run, but also their mental well-being in the short-run'. Dehghan et al. (2011) and Soedergren et al. (2012) find a positive association between $F \& V$ intake and various health behaviours but make no claims about life-satisfaction. Grant et al. (2009) find that healthy behaviours have a significant impact on the life-satisfaction of young adults as do Huang and Humphreys (2012), who consider self-reported happiness in the US.

Both men and women gain happiness from participation in physical activity though men appear to benefit more from participation than women. Richards et al. (2015) find a significant association between the volume of physical activity and happiness in a large sample from 15 European countries. Zhang and Chen (2019), in a systematic review of the relationship between physical activity and happiness also find positive associations between physical activity and happiness.

What implications might our findings have for policy? Given the amount of information provided by health professionals regarding the impact of lifestyle on health, it is clearly not a lack of information that mitigates against healthy lifestyles. The fact that New Year's resolutions often involve such activities is testament to this awareness. The fact, however, that in the vast majority of cases, New Year's resolutions are broken is also testament to the fact that there are other factors at play here. Chief amongst these is the ability to delay gratification. Thaler and Shefrin (1981) identify a number of devices to help with such self-control including monitoring as is done by calorie counting systems or commitment devices (such as natural clinics which enforce a certain lifestyle while in their environs). Certain types of nudge have been suggested in the work by Loewenstein and co-authors related to asymmetric paternalism to improve health behaviours (Loewenstein et al., 2007). Thaler and Shefrin (1981) argued that the planner has different objectives from the doer and it is clear that the planner who sets New Year's resolutions is, in many cases, defeated by the doer who breaks them by concentrating on short term consumption gains. This division seems to be closely related to the human brain function, something long recognized by neuroscientists (e.g. Bjork et al., 2009; Figner et al., 2010; McClure et al., 2007). Behavioural nudges that 
help the planning self to reinforce long-term objectives are likely to be especially helpful in maintaining a healthy lifestyle.

Our study has a number of limitations. While the consumption of F\&V and sports activity are important components of lifestyle, there are clearly other aspects that could be considered. More precise measures of exercise including walking, cycling etc., smoking habits and alcohol consumption as well as more precise measures of healthy eating including the consumption of brown bread, organic produce would have been helpful. Second, our analysis is a cross-sectional one, as the data for delayed gratification and lifestyle are only available in a single wave. However, this implies that we are unable to control for individual differences in our estimation, which would have been possible in a panel dataset. Third, it is possible that genetic factors or personality might influence people's lifestyle choices as well as their ability to delay gratification and we were unable to test for this. Future research might seek to consider the effect of both these factors, as there is some evidence that people who score low on conscientiousness and high on neuroticism for example, find it harder to stick to healthy lifestyle decisions (e.g. Mroczek et al., 2009; Munafo et al., 2007; Terracciano et al., 2008).

Many factors in recent decades have pushed us towards healthy eating and exercise. In the last decade or so, an increasing number of people have shifted towards vegetarian and even vegan diets as well as towards more exercise with increasing cycling and walking. These factors include the costs to the environment and the sustainability of various kinds of dairy and cattle farming as well as the costs to health and therefore to the NHS of poor diet and lack of exercise. By analysing the impact of these shifts on individual well-being in this paper, we consider whether these changes come at the cost of both affective pleasure and/or long term life satisfaction. If the shifts in lifestyle help sustainability of the environment, public finances (especially of the NHS) and at the same time, improve individual life satisfaction, then it is a clear win-win.

\section{Appendix}

See Tables 8, 9, 10, 11, 12, 13, 14 and 15 . 
Table 8 Regression variable statistics

\begin{tabular}{|c|c|c|c|c|}
\hline \multicolumn{5}{|l|}{ All $(14,159$ obs $)$} \\
\hline Variable & Mean & SD & Min & Max \\
\hline Life satisfaction & 5.006 & 1.491 & 1 & 7 \\
\hline Portions of Fruit and Veg $(F \& V)$ & 3.864 & 1.896 & 1 & 8 \\
\hline Sports activity & 3.553 & 2.884 & 0 & 10 \\
\hline Female & 0.581 & 0.493 & 0 & 1 \\
\hline White & 0.925 & 0.263 & 0 & 1 \\
\hline \multicolumn{5}{|l|}{ Age group (ref: 45-54) } \\
\hline Aged 16-24 & 0.086 & 0.281 & 0 & 1 \\
\hline Aged 25-34 & 0.162 & 0.368 & 0 & 1 \\
\hline Aged 35-44 & 0.268 & 0.443 & 0 & 1 \\
\hline Aged 55-64 & 0.247 & 0.431 & 0 & 1 \\
\hline \multicolumn{5}{|l|}{ Marital status (ref: never married) } \\
\hline Married & 0.554 & 0.497 & 0 & 1 \\
\hline Cohabiting & 0.140 & 0.347 & 0 & 1 \\
\hline Separated & 0.020 & 0.139 & 0 & 1 \\
\hline Divorced & 0.075 & 0.263 & 0 & 1 \\
\hline Widowed & 0.016 & 0.126 & 0 & 1 \\
\hline \multicolumn{5}{|c|}{ Highest qualification (ref: no qualifications) } \\
\hline Degree and higher & 0.300 & 0.458 & 0 & 1 \\
\hline Other higher education & 0.143 & 0.350 & 0 & 1 \\
\hline A-level & 0.215 & 0.411 & 0 & 1 \\
\hline GCSE & 0.207 & 0.405 & 0 & 1 \\
\hline Other qualification & 0.077 & 0.267 & 0 & 1 \\
\hline \multicolumn{5}{|c|}{ Age of the youngest child (ref: no children under 16) } \\
\hline Aged 0-2 & 0.095 & 0.294 & 0 & 1 \\
\hline Aged 3-4 & 0.054 & 0.227 & 0 & 1 \\
\hline Aged 5-11 & 0.141 & 0.348 & 0 & 1 \\
\hline Aged $12-15$ & 0.070 & 0.255 & 0 & 1 \\
\hline \multicolumn{5}{|l|}{ Economic activity (ref: employed) } \\
\hline Unemployed & 0.046 & 0.209 & 0 & 1 \\
\hline Retired & 0.068 & 0.251 & 0 & 1 \\
\hline Education & 0.068 & 0.252 & 0 & 1 \\
\hline Not in the labour market & 0.029 & 0.168 & 0 & 1 \\
\hline Log (equivalised income) & 7.538 & 0.639 & -1.77 & 9.84 \\
\hline Long-standing illness & 0.299 & 0.458 & 0 & 1 \\
\hline Urban area & 0.752 & 0.432 & 0 & 1 \\
\hline Control over life & 3.097 & 1.370 & 1.00 & 6.00 \\
\hline Delay 1 & 5.199 & 2.836 & 0 & 10 \\
\hline Delay 8 & 6.173 & 2.515 & 0 & 10 \\
\hline
\end{tabular}

Delay 1 is reverse coded and refers to the question "I would have a hard time sticking with a special, healthy diet"

Delay 8 refers to the question "I have always tried to eat healthy because it pays off in the long run" 


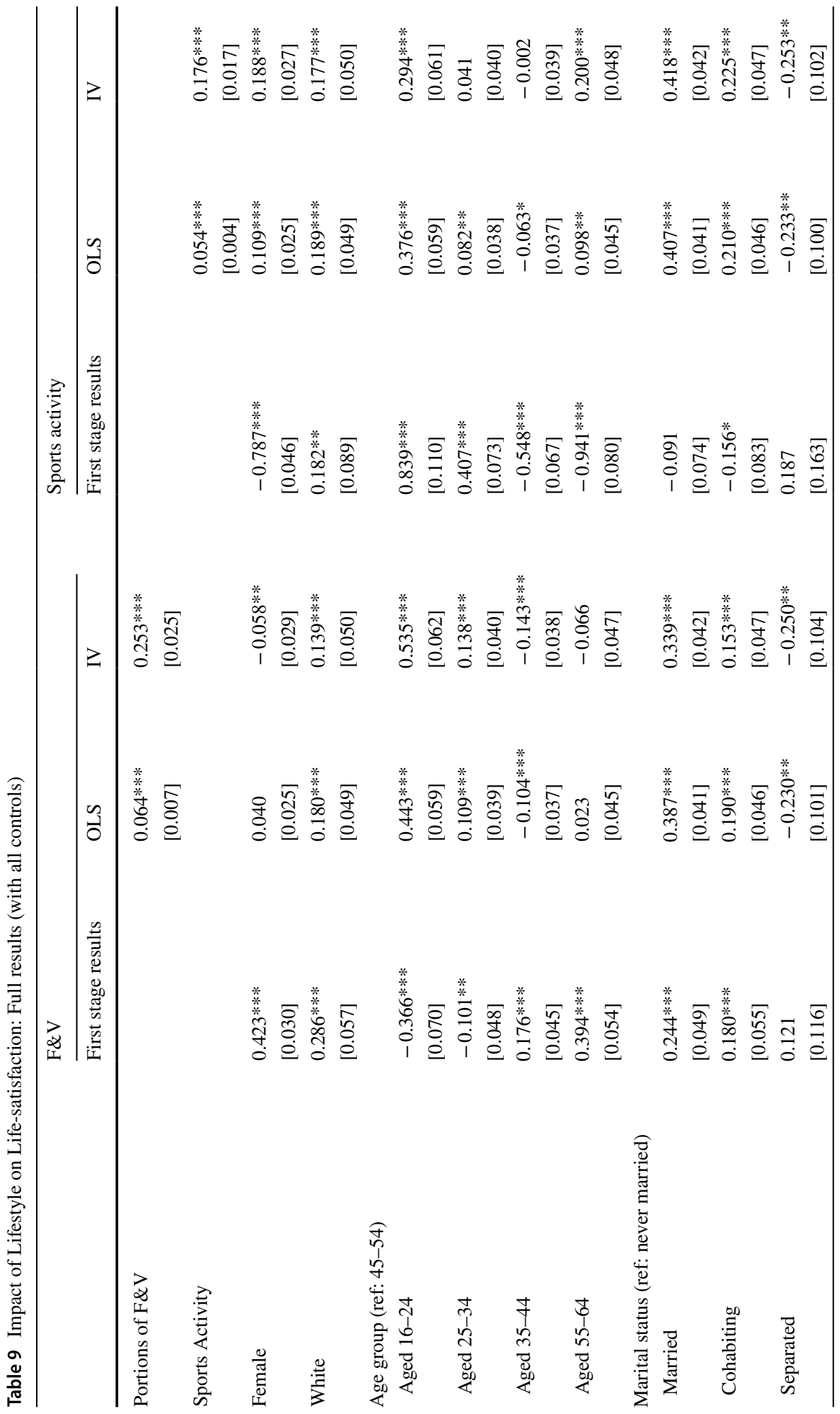




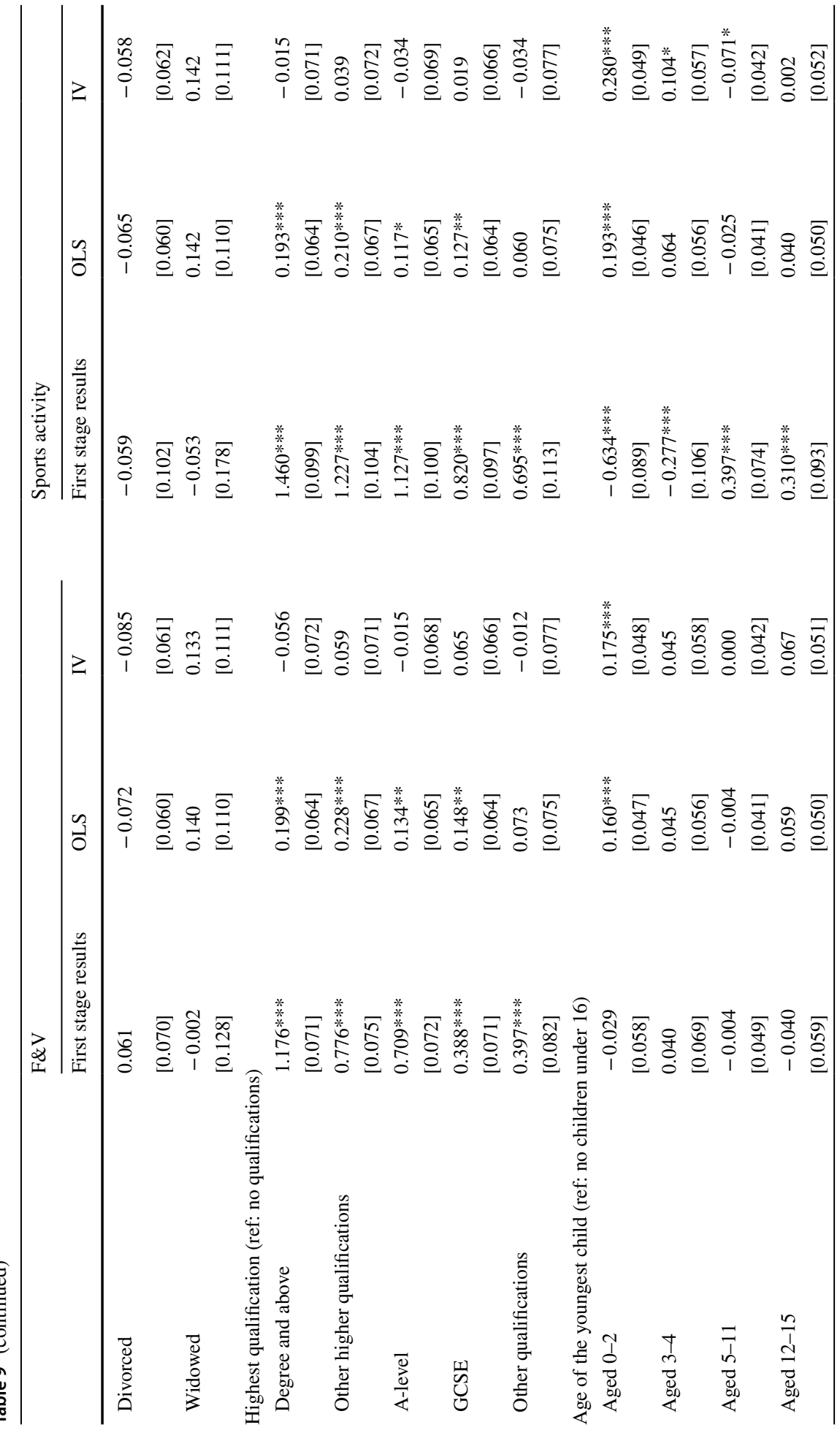




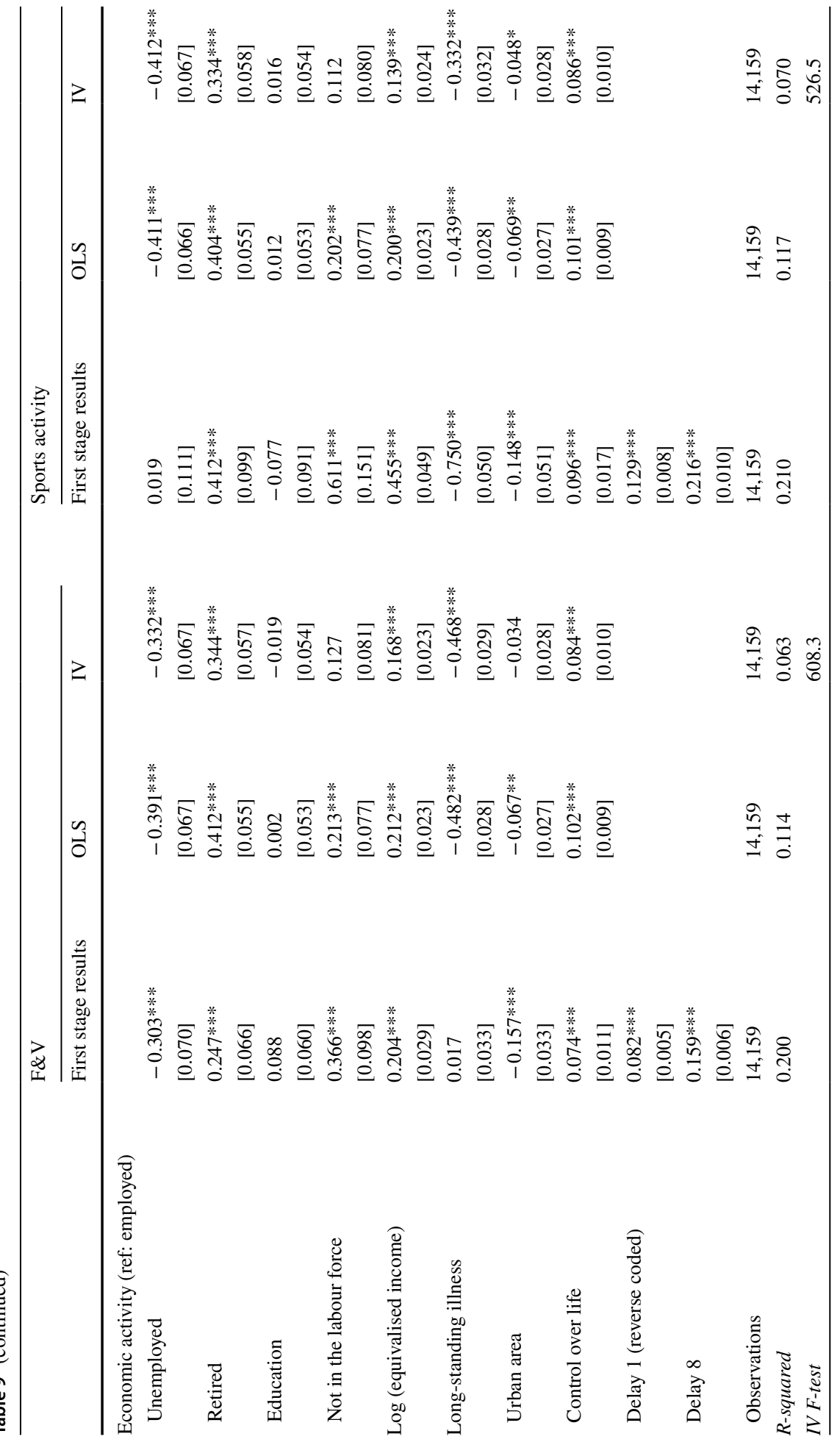




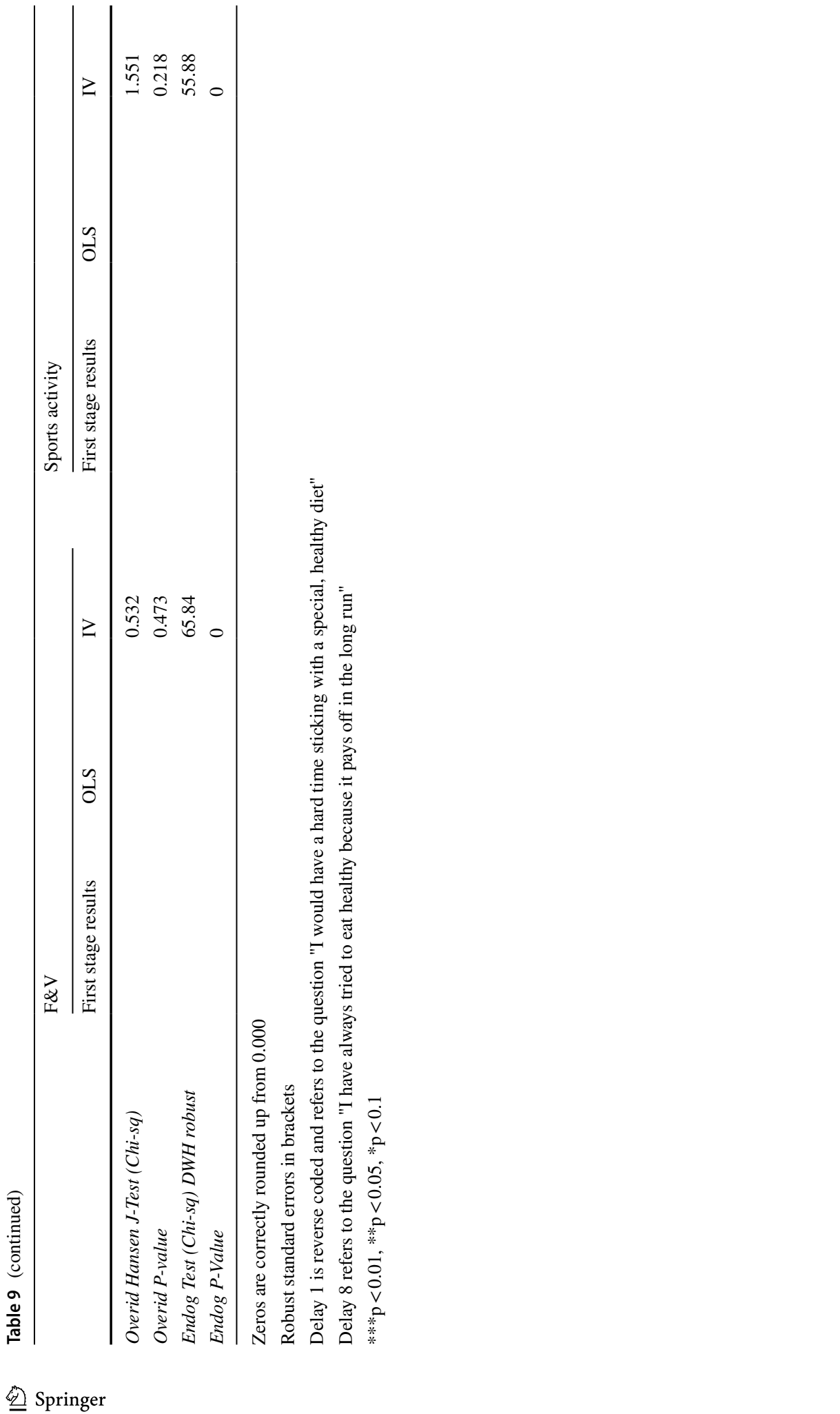


Table 10 Comparison of instruments on their own and together

\begin{tabular}{|c|c|c|c|c|}
\hline & \multicolumn{4}{|l|}{$\mathrm{F} \& \mathrm{~V}$} \\
\hline & OLS & Both instruments & Delay 1 & Delay 8 \\
\hline \multirow[t]{2}{*}{ Portions of $\mathrm{F} \& \mathrm{~V}$} & $0.064 * * *$ & $0.253 * * *$ & $0.232 * * *$ & $0.262 * * *$ \\
\hline & {$[0.007]$} & {$[0.025]$} & {$[0.038]$} & {$[0.028]$} \\
\hline Obs & 14,159 & 14,159 & 14,159 & 14,159 \\
\hline$R$-squared & 0.114 & 0.063 & 0.074 & 0.058 \\
\hline$I V F$ test & & 608.3 & 492.7 & 892.3 \\
\hline Overid Hansen J Test (Chi-sq) & & 0.532 & & \\
\hline Overid P-value & & 0.473 & & \\
\hline Endog test (Chi-sq) DWH robust & & 65.84 & 21.25 & 54.74 \\
\hline \multirow[t]{3}{*}{ Endog $P$-value } & & 0 & 0 & 0 \\
\hline & \multicolumn{4}{|c|}{ Sports activity } \\
\hline & OLS & Both instruments & Delay 1 & Delay 8 \\
\hline \multirow[t]{2}{*}{ Sports activity } & $0.054 * * *$ & $0.176^{* * * *}$ & $0.153 * * *$ & $0.189^{* * *}$ \\
\hline & {$[0.004]$} & {$[0.017]$} & {$[0.025]$} & {$[0.020]$} \\
\hline Obs & 14,159 & 14,159 & 14,159 & 14,159 \\
\hline$R$-squared & 0.117 & 0.070 & 0.086 & 0.059 \\
\hline IV F test & & 526.5 & 485.2 & 752.3 \\
\hline Overid Hansen J Test (Chi-sq) & & 1.551 & & \\
\hline Overid P-value & & 0.218 & & \\
\hline Endog test (Chi-sq) DWH robust & & 55.88 & 17.15 & 48.52 \\
\hline Endog P-value & & 0 & 0 & 0 \\
\hline
\end{tabular}

Note, there is no over-identification test available when there is only one instrument

Zeros are correctly rounded up from 0.000

Robust standard errors in brackets

Includes controls for white, age group, marital status, age of the youngest child, highest qualification, economic activity, log of equivalised (by the OECD equivalence scale) household income, urban area, long standing illness

Delay 1 is reverse coded and refers to the question "I would have a hard time sticking with a special, healthy diet"

Delay 8 refers to the question "I have always tried to eat healthy because it pays off in the long run" $* * * \mathrm{p}<0.01, * * \mathrm{p}<0.05, * \mathrm{p}<0.1$ 


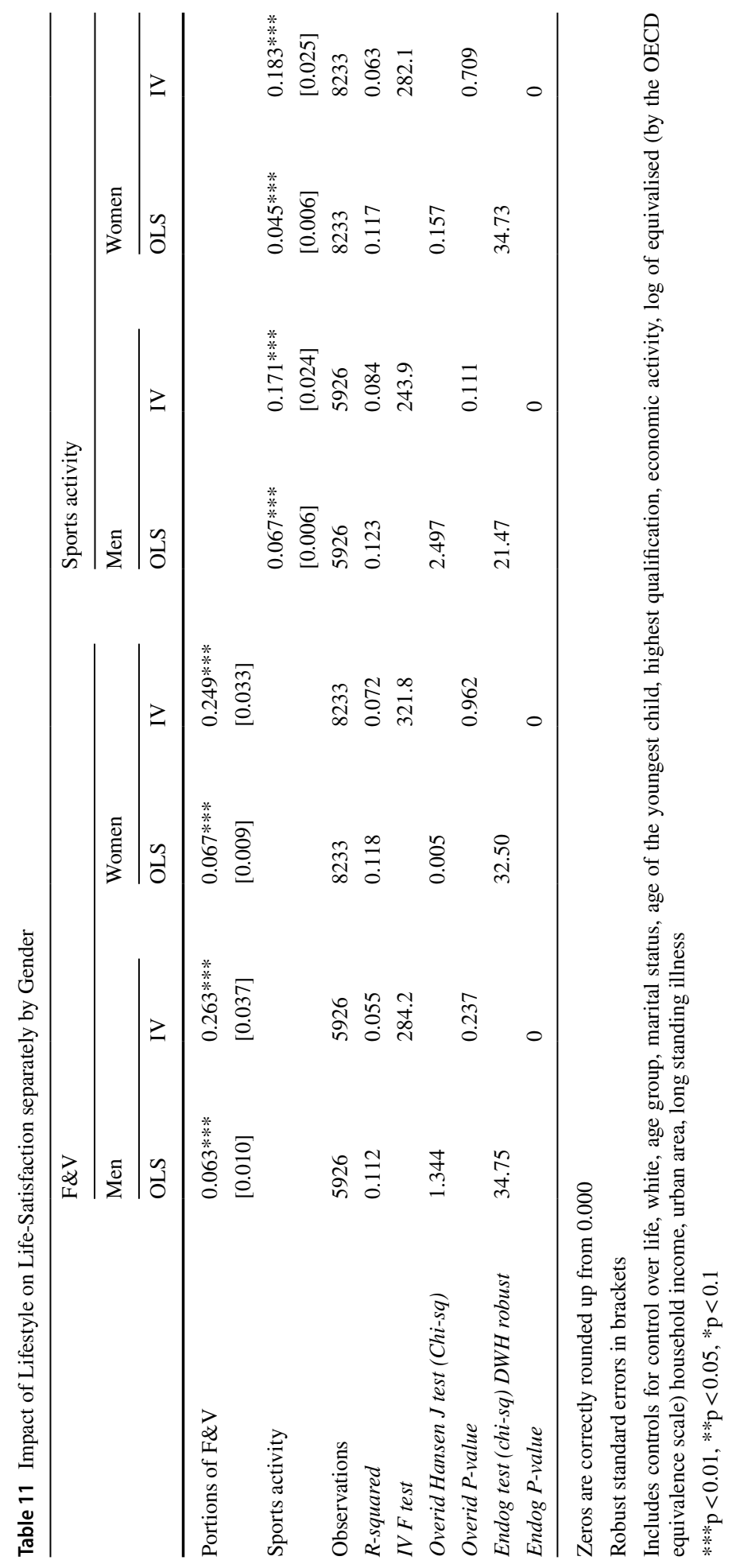




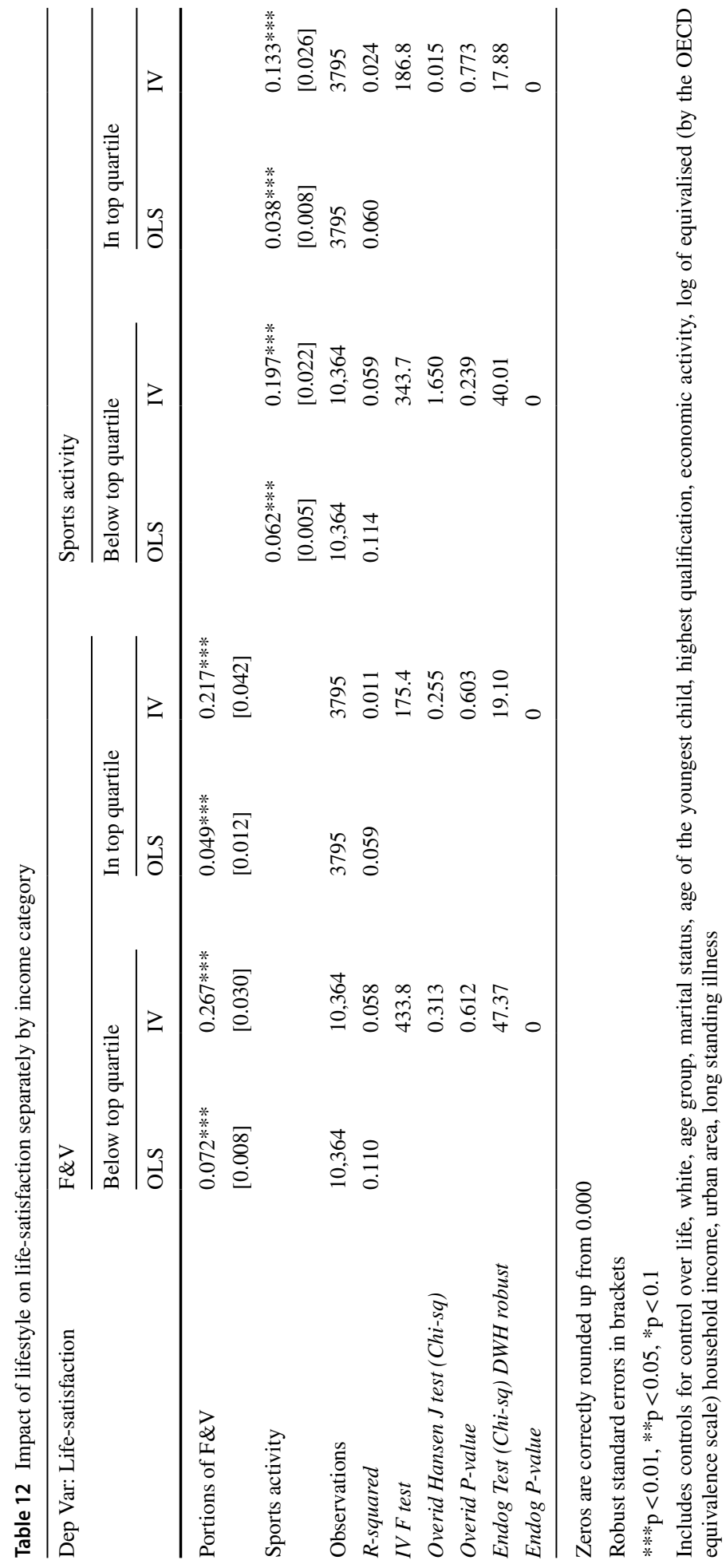




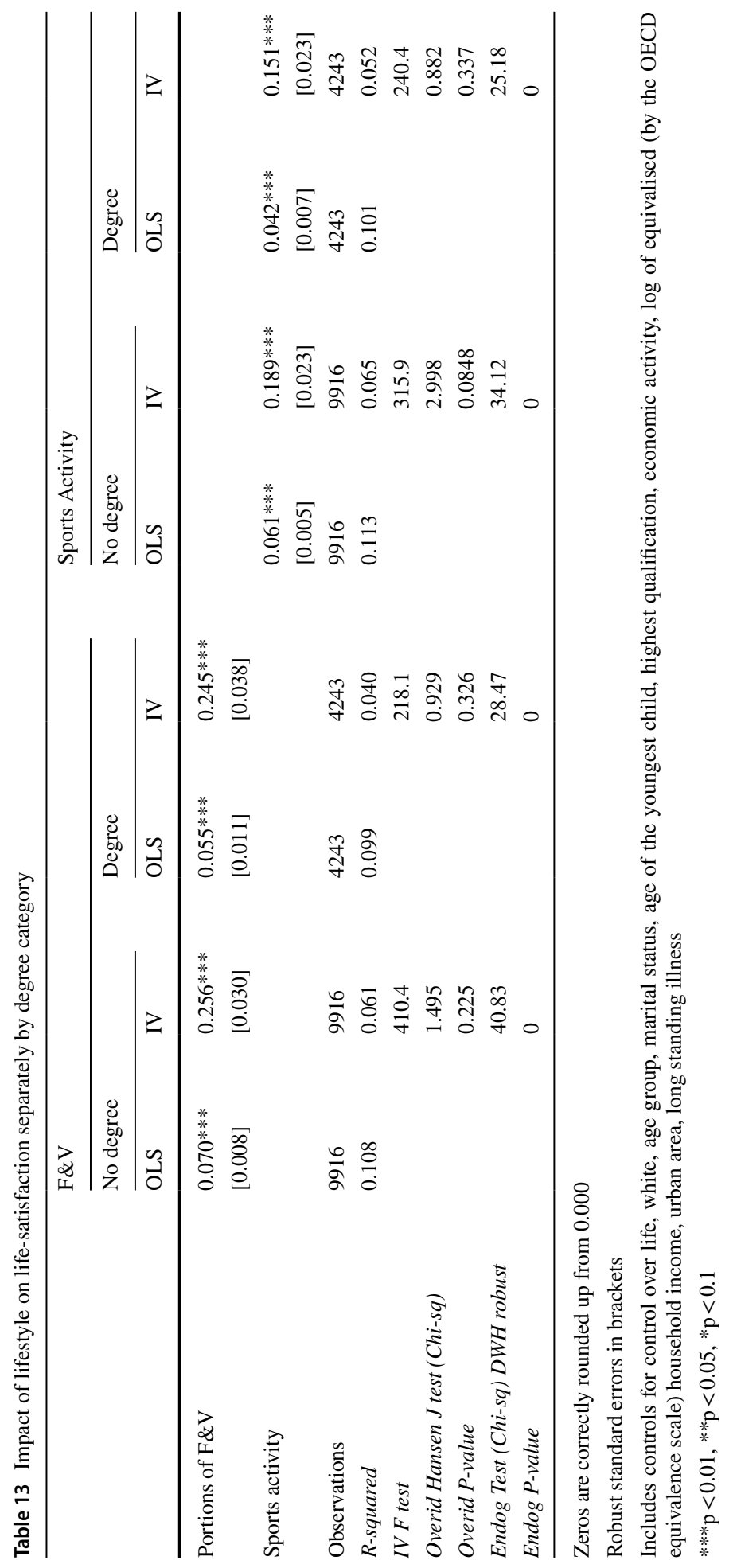




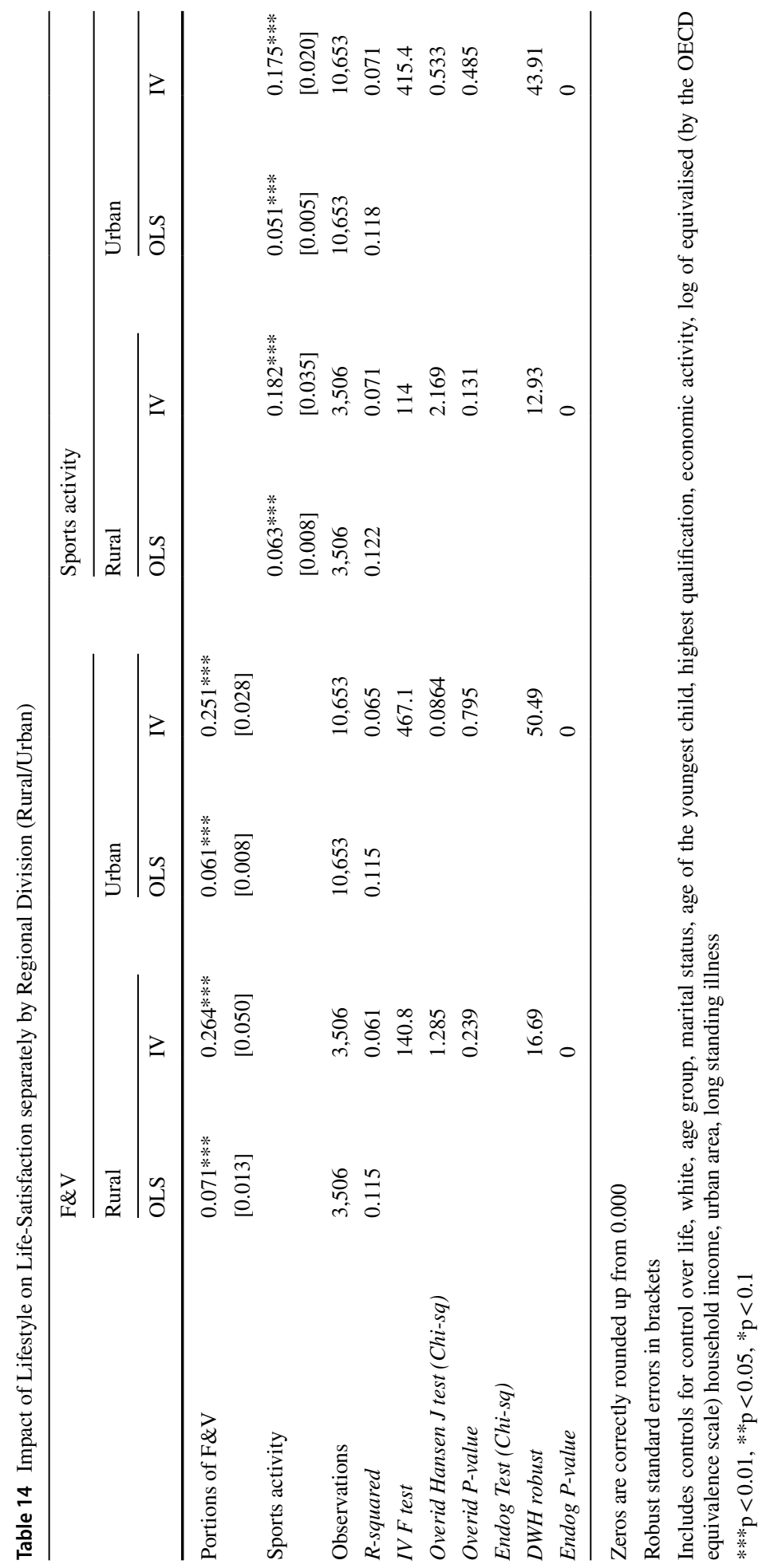


Table 15 Impact of lifestyle on life-satisfaction separately by age group

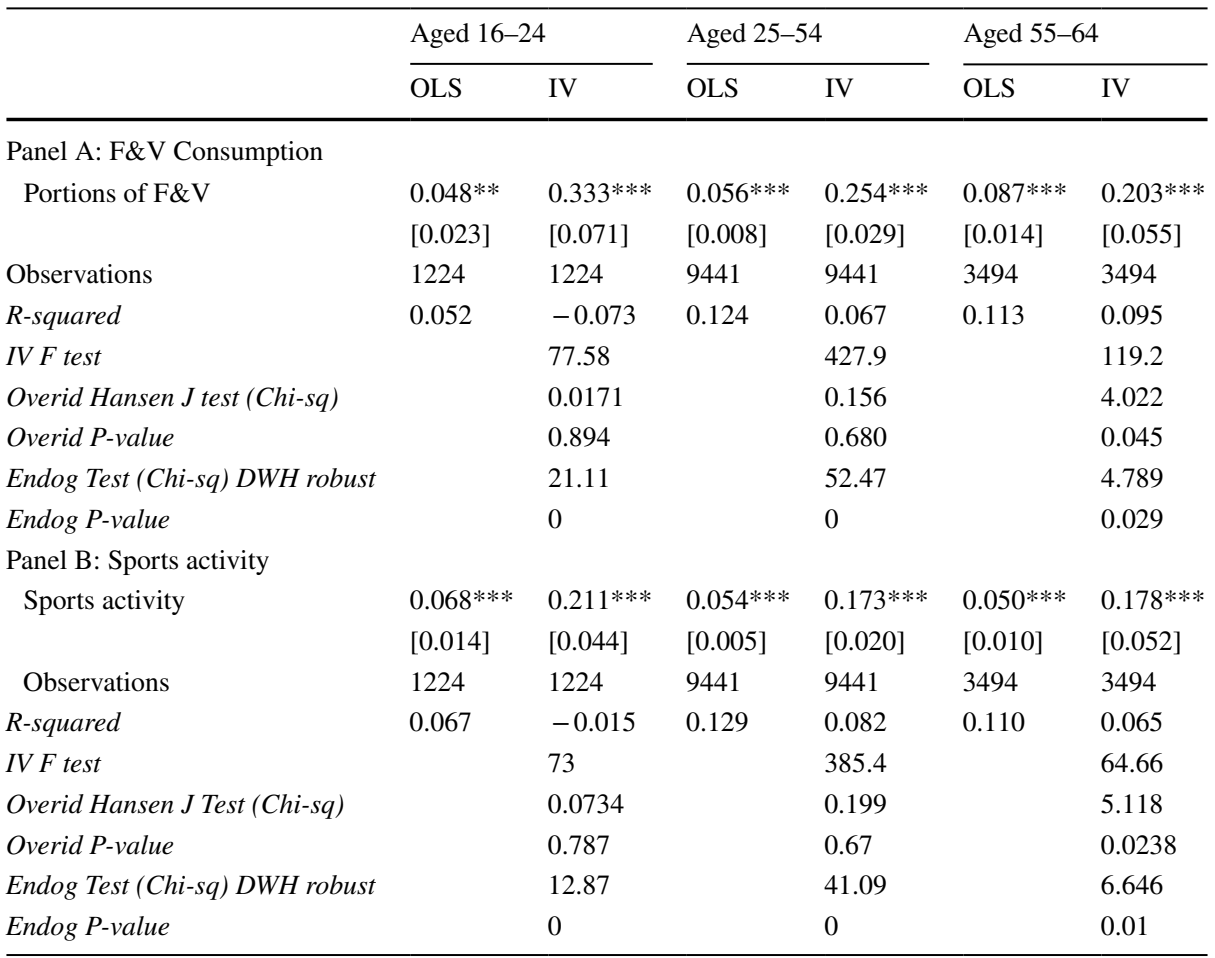

Zeros are correctly rounded up from 0.000

Robust standard errors in brackets

Includes controls for gender, control over life, white, whether live with spouse/partner, age of the youngest child, highest qualification, log of equivalised (by the OECD equivalence scale) household income, employed, unemployed, urban area, long standing illness

$* * * \mathrm{p}<0.01, * * \mathrm{p}<0.05,{ }^{*} \mathrm{p}<0.1$

Funding The research in this paper has not been funded by any research grants.

\section{Declarations}

Conflict of Interest The authors declare that they have no conflict of interest.

Open Access This article is licensed under a Creative Commons Attribution 4.0 International License, which permits use, sharing, adaptation, distribution and reproduction in any medium or format, as long as you give appropriate credit to the original author(s) and the source, provide a link to the Creative Commons licence, and indicate if changes were made. The images or other third party material in this article are included in the article's Creative Commons licence, unless indicated otherwise in a credit line to the material. If material is not included in the article's Creative Commons licence and your intended use is not permitted by statutory regulation or exceeds the permitted use, you will need to obtain permission directly from the copyright holder. To view a copy of this licence, visit http://creativecommons.org/licenses/by/4.0/. 


\section{References}

Benhabib, J., \& Bisin, A. (2005). Modeling internal commitment mechanisms and self-control: A neuroeconomics approach to consumption-saving decisions. Games and Economic Behavior, 52(2), 460-492. https://doi.org/10.1016/j.geb.2004.10.004

Bjork, J. M., Momenan, R., \& Hommer, D. W. (2009). Delay discounting correlates with proportional lateral frontal cortex volumes. Biological Psychiatry, 65(8), 710-713. https://doi.org/10.1016/j.biopsych. 2008.11.023

Blanchflower, D. G., Oswald, A. J., \& Stewart-Brown, S. (2013). Is psychological well-being linked to the consumption of fruit and vegetables? Social Indicators Research, 114(3), 785-801. https://doi.org/10. 1007/s11205-012-0173-y

Cobb-Clark, D. A., Kassenboehmer, S. C., \& Schurer, S. (2014). Healthy habits: The connection between diet, exercise, and locus of control. Journal of Economic Behavior \& Organization, 98, 1-28. https:// doi.org/10.1016/j.jebo.2013.10.011

Cohen, J. D., Dunbar, K., \& McClelland, J. L. (1990). On the control of automatic processes: A parallel distributed processing account of the Stroop effect. Psychological Review, 97(3), 332.

Dehghan, M., Akhtar-Danesh, N., \& Merchant, A. T. (2011). Factors associated with fruit and vegetable consumption among adults. Journal of Human Nutrition and Dietetics, 24(2), 128-134. https://doi.org/ 10.1111/j.1365-277X.2010.01142.x

Ferrer-i-Carbonell, A., \& Frijters, P. (2004). How important is methodology for the estimates of the determinants of happiness? The Economic Journal, 114(497), 641-659.

Figner, B., Knoch, D., Johnson, E. J., Krosch, A. R., Lisanby, S. H., Fehr, E., \& Weber, E. U. (2010). Lateral prefrontal cortex and self-control in intertemporal choice. Nature Neuroscience, 13(5), 538-539. https://doi.org/10.1111/j.1468-0297.2004.00235.x

Fudenberg, D., \& Levine, D. K. (2006). A dual-self model of impulse control. American Economic Review, 96(5), 1449-1476. https://doi.org/10.1257/aer.96.5.1449

Graham, C., Eggers, A., \& Sukhtankar, S. (2004). Does happiness pay?. In Challenges for quality of life in the contemporary world (pp. 179-204). Springer, Dordrecht. https://doi.org/10.1016/j.jebo.2003.09. 002

Grant, N., Wardle, J., \& Steptoe, A. (2009). The relationship between life satisfaction and health behavior: A cross-cultural analysis of young adults. International Journal of Behavioral Medicine, 16(3), 259-268. https://doi.org/10.1007/s12529-009-9032-x

Grossman, M. (1972). On the concept of health capital and the demand for health. Journal of Political Economy, 80(2), 223-255.

Hayashi, F. (2000). Econometrics. Princeton University Press.

Hoerger, M., Quirk, S. W., \& Weed, N. C. (2011). Development and validation of the Delaying Gratification Inventory. Psychological Assessment, 23(3), 725. https://doi.org/10.1037/a0023286

Huang, H., \& Humphreys, B. R. (2012). Sports participation and happiness: Evidence from US microdata. Journal of Economic Psychology, 33(4), 776-793. https://doi.org/10.1016/j.joep.2012.02.007

Kenny, A., \& Charles Kenny (2011). Life, liberty and the pursuit of utility: Happiness in philosophical and economic thought (Vol. 7). Andrews UK Limited. https://doi.org/10.1080/00213624.2007.11507075

Loewenstein, G. (1996). Out of control: Visceral influences on behavior. Organizational Behavior and Human Decision Processes, 65(3), 272-292.

Loewenstein, G., Brennan, T., \& Volpp, K. G. (2007). Asymmetric paternalism to improve health behaviors. JAMA, 298(20), 2415-2417. https://doi.org/10.1001/jama.298.20.2415

Loewenstein, G., O’Donoghue, T., \& Bhatia, S. (2015). Modeling the interplay between affect and deliberation. Decision, 2(2), 55. https://doi.org/10.1037/dec0000029

McClure, A. C., Dal Cin, S., Gibson, J., \& Sargent, J. D. (2006). Ownership of alcohol-branded merchandise and initiation of teen drinking. American Journal of Preventive Medicine, 30(4), 277-283.

McClure, S. M., Ericson, K. M., Laibson, D. I., Loewenstein, G., \& Cohen, J. D. (2007). Time discounting for primary rewards. Journal of Neuroscience, 27(21), 5796-5804. https://doi.org/10.1016/j.amepre. 2005.11.004

Mill, J. S. (1859). Utilitarianism (1863). Utilitarianism, Liberty, Representative Government, 7-9.

Mroczek, D. K., Spiro, A., III., \& Turiano, N. A. (2009). Do health behaviors explain the effect of neuroticism on mortality? Longitudinal findings from the VA Normative Aging Study. Journal of Research in Personality, 43(4), 653-659. https://doi.org/10.1016/j.jrp.2009.03.016

Mujcic, R., \& Oswald, A. J. (2016). Evolution of well-being and happiness after increases in consumption of fruit and vegetables. American Journal of Public Health, 106(8), 1504-1510. https://doi.org/10. 2105/AJPH.2016.303260 
Munafo, M. R., Zetteler, J. I., \& Clark, T. G. (2007). Personality and smoking status: A meta-analysis. Nicotine \& Tobacco Research, 9(3), 405-413. https://doi.org/10.1080/14622200701188851

National Institutes of Health (2009). NIH science of behavior change. Retrieved 7 June 2021, from https:// commonfund.nih.gov/sites/default/files/SOBC_Meeting_Summary_2009.pdf

Ocean, N., Howley, P., \& Ensor, J. (2019). Lettuce be happy: A longitudinal UK study on the relationship between fruit and vegetable consumption and well-being. Social Science \& Medicine, 222, 335-345. https://doi.org/10.1016/j.socscimed.2018.12.017

Posner, M. I., \& Snyder, C. R. R. (1975). Facilitation and inhibition in the processing of signals. In P. M. A. Rabbitt \& S. Dornic (Eds.), Attention and performance V. New York: Academic Press.

Richards, J., Jiang, X., Kelly, P., Chau, J., Bauman, A., \& Ding, D. (2015). Don't worry, be happy: Crosssectional associations between physical activity and happiness in 15 European countries. BMC Public Health, 15(1), 1-8. https://doi.org/10.1186/s12889-015-1391-4

Ross, D. (1956). Aristotle: The Nicomachean ethics. Oxford University Press.

Ruhm, C. J. (2012). Understanding overeating and obesity. Journal of Health Economics, 31(6), 781-796. https://doi.org/10.1016/j.jhealeco.2012.07.004

Shefrin, H. M., \& Thaler, R. H. (1988). The behavioral life-cycle hypothesis. Economic Inquiry, 26(4), 609-643.

Soedergren, M., McNaughton, S. A., Salmon, J., Ball, K., \& Crawford, D. A. (2012). Associations between fruit and vegetable intake, leisure-time physical activity, sitting time and self-rated health among older adults: Cross-sectional data from the WELL study. BMC Public Health, 12(1), 1-9. https://doi.org/10. 1186/1471-2458-12-551

Terracciano, A., Löckenhoff, C. E., Crum, R. M., Bienvenu, O. J., \& Costa, P. T. (2008). Five-factor model personality profiles of drug users. BMC Psychiatry, 8(1), 1-10. https://doi.org/10.1186/1471244X-8-22

Thaler, R. H., \& Shefrin, H. M. (1981). An economic theory of self-control. Journal of Political Economy, $89(2), 392-406$.

Welsch, H. (2012). Organic food and human health: Instrumental variables evidence (Vol. 349, No. 12). Oldenburg Discussion Papers in Economics.

Zhang, Z., \& Chen, W. (2019). A systematic review of the relationship between physical activity and happiness. Journal of Happiness Studies, 20(4), 1305-1322. https://doi.org/10.1007/s10902-018-9976-0

Publisher's Note Springer Nature remains neutral with regard to jurisdictional claims in published maps and institutional affiliations. 